\title{
Principais Aspectos do Direito Marítimo e sua Relação com a Lex Mercatoria e Lex Maritima
}

\author{
Osvaldo Agripino de Castro Junior ${ }^{1}$
}

\begin{abstract}
Resumo: O artigo objetiva apresentar, de forma introdutória, os principais aspectos do Direito Marítimo e sua relação com a Lex Mercatoria e a Lex Maritima, a fim de que essa fonte de direito seja recepcionada de forma crítica pelo direito brasileiro, com base na ordem pública, portanto, com reservas.
\end{abstract}

Palavras-chave: Direito Marítimo. Lex Mercatori. Lex Maritima.

\begin{abstract}
This article aims to give a general overview of the main aspects of Brazilian Maritime Law and its relationship with Lex Mercatoria and Lex Maritima, in order to introduce the last one into brazilian law in a critical approach based on the public order, thus, with restrictions.
\end{abstract}

Keywords: Maritime Law; Lex Mercatoria; Lex Maritima .

\section{Introdução}

De forma introdutória e conceitual, este artigo objetiva, em breves notas, contribuir para o Direito Internacional Privado brasileiro por meio do estudo dos principais aspectos do Direito Marítimo $^{2}$ e sua relação com a Lex Mercatoria e Lex Maritima, ora consideradas como os usos e costumes habituais no comércio internacional e no transporte marítimo internacional, bem como indicar bibliografia básica sobre o tema.

1 Professor do Programa de Mestrado e Doutorado em Ciência Jurídica da Univali (www.univali/ppcj) e Coordenador do Grupo de Pesquisa Regulação da Infraestrutura e Juridicidade da Atividade Portuária. Advogado atuante no comércio exterior, transportes e portos. (www.adsadvogados.adv.br).E-mail: agripino@adsadvogados.adv.br.

2 Sobre o tema, uma análise com maior profundidade e que aborda vários outros temas relevantes para o Direito Marítimo, é encontrada, em treze artigos que tratam da regulação econômica do setor de transportes marítimos, contratos internacionais, cabotagem, NVOCC, Direito Ambiental Marítimo, Representação do Brasil na IMO, dentre outros, na obra: CASTRO JUNIOR, Osvaldo Agripino de. (org.) Direito Marítimo, Regulação e Desenvolvimento. Prefácio Comte. Wesley Collyer. Belo Horizonte: Fórum, 2011. 
Assim, o artigo pretende, ainda, contribuir para o revigoramento da Teoria Geral do Direito Marítimo e do Direito Internacional Privado brasileiros e difundir o Direito Marítimo, disciplina autônoma ${ }^{3}$ que tem como objeto regular as relações jurídicas que se dão em torno do navio, como contratos de transporte de bens e pessoas, contratos de afretamento de embarcações, responsabilidade civil, ressaltando-se que o navio opera num ambiente de regulação interna (ANTAQ - Agência Nacional de Transportes Aquaviários -, CONIT - Conselho Nacional de Integração de Políticas de Transportes -, DPC - Diretoria de Portos e Costas -, dentre outros) e externa (IMO - Internacional Maritime Organization -, OMC Organização Mundial do Comércio -, OMA - Organização Mundial das Aduanas -, dentre outros).

O Direito Marítimo, como sofre grande influência da economia internacional, é uma disciplina com forte grau de dinamismo e que, portanto, requer um processo constante de atualização. Além disso, há uma preocupação permanente em reconhecer o Direito Marítimo e sua relação com o Direito Regulatório do Transporte Aquaviário e da Atividade Portuária, como instrumentos importantes para a eficácia dos objetivos fundamentais da República Federativa do Brasil. ${ }^{4}$

O Direito e a Regulação devem atender, preservado o interesse público, as demandas dos agentes econômicos, nesse caso usuários dos serviços de transportes marítimos, aumentar a eficiência das transações comerciais e, conseqüente, reduzir os seus custos, de forma sustentável. Nesse cenário, a crítica da Lex Maritima, ou sua incorporação com a fil-

3 Nessa linha de revigoramento do Direito Marítimo brasileiro sem, contudo, aprofundar as relações da disciplina nos ambientes interno (agência reguladora independente ANTAQ) e internacional (supranacional - OMC, UNCTAD e IMO) indicamos: DOS ANJOS, José Haroldo; GOMES, Carlos Rubens Caminha. Curso de Direito Marítimo. Rio de Janeiro: Renovar, 1992. Outra obra interessante da qual tivemos oportunidade de colaborar é: MARTINS, Eliane Maria Octaviano. Curso de Direito Marítimo. Vols. I e II, 3. ed. São Paulo: Manole, 2008.

4 Conforme artigo $3^{\circ}$, da Lei Maior: Art. $3^{\circ}$ Constituem objetivos fundamentais da República Federativa do Brasil: I - construir uma sociedade livre, justa e solidária; II - garantir o desenvolvimento nacional; III - erradicar a pobreza e a marginalização e reduzir as desigualdades sociais e regionais; IV - promover o bem de todos, sem preconceitos de origem, raça, sexo, cor, idade e quaisquer outras formas de discriminação. 
tragem com fundamento na ordem pública, é relevante, não obstante parte da doutrina estrangeira defendê-la como importante para a uniformização do Direito Marítimo.

Pretende-se, dessa maneira, tratar da percepção do Direito Marítimo como disciplina que possa contribuir para defesa dos interesses dos usuários dos serviços de transportes marítimos, vez que o Brasil, ao transportar somente $1 \%$ das mercadorias do seu comércio exterior em navios de bandeira própria, tem alto grau de dependência dos transportadores internacionais.

São várias as razões para tal dependência, mas dentre elas podem ser enumeradas a falta de uma política de Marinha Mercante de longo prazo, ou seja, política de Estado, bem como a concorrência desleal que as empresas de navegação brasileiras sofrem dos navios de bandeira de conveniência e a ineficácia do Poder Público para combater tais ilegalidades, ${ }^{5}$ especialmente contrato de transporte de adesão, com cláusulas abusivas, com lei aplicável decorrente de convenção não ratificada pelo Brasil e foro no estrangeiro, fundados na Lex Maritima.

Diante de tais fatos, pretende-se contribuir para a difusão de um Direito Marítimo que procure defender os interesses dos usuários dos serviços de transportes marítimo - cargo owners, tendo em vista que é difícil conciliar em termos convencionais os interesses dos países possuidores de navios (ship owners countries), categoria a qual não pertence o Brasil. A criação e a recepção de uma convenção internacional para equilibrar os interesses dos países ship owners x países cargo onwers, não é impossível, mas é um tour de force, que precisa de um foro multilateral cooperativo como a OMC para que se torne realidade. Nesse quadro, a percepção da Lex Maritima de forma crítica é relevante.

Tal assertiva tem fundamento na linha de atuação que o Brasil adotou ao não ratificar qualquer das quatro convenções que regulam a

5 Sobre o tema da concorrência desleal no setor de transportes e portos, deve-se mencionar o I Seminário UNIVALI e CADE sobre Defesa da Concorrência e Regulação Econômica de Transportes e Portos, inédito no Brasil, realizado no dia 30 de março de 2010, a pedido do CADE, na UNIVALI, Campus de Itajaí, sob coordenação do Programa de Mestrado e Doutorado em Ciência Jurídica da mesma universidade. 
responsabilidade civil no transporte marítimo, apesar dos usuários brasileiros, regra geral, sem opção de transporte ou orientação regulatória, aceitarem as cláusulas do Bill of lading - conhecimento de embarque marítimo - que se fundamentam em tais normas por meio da fonte de direito denominada Lex Maritima. ${ }^{6}$

O texto será desenvolvido de forma interdisciplinar em duas partes. A Parte 1 trata de alguns conceitos relevantes do Direito Marítimo, conceitua-o e relaciona-o com outras disciplinas jurídicas e ramos do conhecimento. A Parte 2 discorre sobre a relação da citada disciplina com outros ramos do Direito, a Lex Mercatoria e a Lex Maritima. Por fim, são feitas as conclusões para melhor percepção critica da Lex Maritima no direito brasileiro. ${ }^{7}$

\section{Direito Marítimo: conceitos relevantes}

\subsubsection{Transporte Marítimo no Mundo Globalizado}

Deve-se acrescentar que o globo terrestre possui $27 \%$ de sua superfície formada por continente e $73 \%$ de espaços marítimos (MOURA, 1991), fazendo com que cerca de mais de $90 \%$ das mercadorias sejam transportadas pelo mar. A atividade comercial que envolve o transporte aquaviário (business shipping) é conceituada como o movimento físico

6 Considerada como usos e costumes do transporte marítimo internacional que, todavia, não podem prevalecer no direito brasileiro se violarem a ordem pública, nos termos do artigo 17 da Lei de Introdução ao Código Civil, que assim dispõe: “Art. $17^{\circ}$ - As leis, atos e sentenças de outro país, bem como quaisquer declarações de vontade, não terão eficácia no Brasil, quando ofenderem a soberania nacional, a ordem pública e os bons costumes." Embora haja autonomia da vontade nos contratos internacionais, essa autonomia não é absoluta, mas relativa, vez que encontra limite no ordenamento jurídico pátrio, seja na LICC, seja na Teoria Geral dos Contratos do Código Civil.

7 Pesquisa de jurisprudência realizada na Jurisprudência Unificada da página eletrônica do Portal da Justiça Federal da expressão Lex Maritima, não encontrou julgado, mas com Lex Mercatoria, obteve-se seis julgados, relativos à homologação de sentença estrangeira e carta rogatória, todavia, nenhum relacionado ao transporte marítimo. BRASIL. Portal da Justiça Federal. Administrado pelo Conselho da Justiça Federal. Jurisprudência Unificada. Disponível em:<www.jf.jus.br/cjf>. Acesso em: 10 abr. 2010. 
de bens e pessoas de portos fornecedores para portos de demanda assim como as atividades exigidas para apoiar a facilitação de tal movimento. Segundo Kendall e Buckley (2001, p. 7):

[...] o transporte de mercadoria por navios é o que dá vitalidade à economia de muitos países, situados ou não no litoral [...]. Com quase três quartos da superfície da terra coberta por água. O transporte marítimo necessariamente possui um papel muito relevante no comércio internacional.

A economia do transporte marítimo é bastante complexa, seja pela quantidade de indústrias e serviços que o dinâmico cluster marítimo ${ }^{8}$ demanda, seja pelos altos valores necessários para uma expedição marítima. ${ }^{9}$ Trata-se de indústria que demanda uma grande sinergia entre várias cadeias de fornecedores de produtos (mineração, siderurgia, construção de naval, ${ }^{10}$ dentre outros) e prestadores de serviços (engenharia naval, finanças, assessoria jurídica, dentre outros), de modo que o papel do Estado, por meio da regulação setorial independente, é fundamental.

8 Acerca do cluster marítimo gerado pelo desenvolvimento da cabotagem brasileira: CASTRO JUNIOR, Osvaldo Agripino de; LACHMANN, Marianne Von. $O$ valor da cabotagem brasileira na visão dos transportadores. Apresentação realizada no I Seminário Nacional sobre Cabotagem. Realização ANTAQ e Syndarma. Disponível em: $<$ www.regulacao.gov.br>. Acesso em: 20 dez. 2009. Na Europa: WIJNOLST N.(dir.) Dynamic: European Maritime Clusters. Amsterdam: IOS Press, 2006.

9 Sobre o tema: STOPFORD, Martin. Maritime Economics. London and New York: Routledge, 2004. E: BRANCH, Alan E. Elements of Shipping. 8. ed. London and New York: Routledge, 2007.

${ }^{10} \mathrm{~A}$ construção naval tem exercido um papel fundamental na economia dos países industrializados, de modo que é relevante o estudo comparativo do processo histórico do papel do Estado no financiamento desse setor, inclusive sobre a economia da bandeira de conveniência (flagging out) exercida pelos governos e o papel da OCDE e da Coréia do Sul. ROSA, Angelo L. Contrariety: Divergent Theories of State Involvement in Shipping Finance Between the United States and the European Union. In: Tulane Maritime Law Journal. vol. 29, 2004-2005, p. 203-206. Recomenda-se a análise do estudo comparado dos microfundamentos do financiamento de projetos orientado à construção naval no Brasil: DA SILVA, Marcello Muniz. Análise da Estrutura de Financiamento à Indústria Naval no Brasil. Dissertação de Mestrado em Engenharia Naval e Oceânica. São Paulo: Escola Politécnica da USP, 2007, 346 p. 
Por sua vez, o grau de especialização das empresas de navegação é grande e o business model do sucesso de tais companhias, em decorrência do dinamismo do comércio internacional, pode mudar no futuro próximo. (LORANGE, 2008). Dessa maneira, não há como entender a economia do setor sem analisar a conjuntura econômica internacional e o papel do transnacionalismo, bem com das entidades de classe dos transportadores marítimos, adiante mencionadas.

\subsubsection{International Chamber of Shipping (ICS)}

A ICS é a principal associação internacional que congrega os transportadores marítimos e compreende associações nacionais de armadores que representam $66 \%$ da tonelagem da frota mercante mundial. Ressalte-se que o Brasil e o Panamá, dentre outros países, não fazem parte da mesma. Criada em 1921, a ICS se preocupa com todas as questões técnicas, jurídicas e políticas que possuem impacto no transporte marítimo internacional.

O Secretariado da ICS é exercido pela Maritime International Secretariat Services Limited (Marisec), que pertence ao ICS e sua organização parceira International Shipping Federation (ISF), adiante tratada. A ICS é engajada ativamente nos seguintes organismos internacionais: International Maritime Organization (IMO), United Nations Division of Ocean Affairs and the Law of the Sea (DOALOS), United Nations Conference on International Trade Law (UNCITRAL), Organization for Economic Co-operation and Development (OECD), World Customs Organization (WCO) e World Trade Organization (WTO).(ICS, 2009).

Além disso, a ICS possui um relacionamento estreito com autoridades marítimas nacionais e com relevantes departamentos e agências da União Europeia. Nos últimos trinta e cinco anos, a ICS tem exercido um papel influente no desenvolvimento, implementação e subsequentes revisões do SOLAS (The International Convention for the Safety of Life at Sea) e da MARPOL (The International Convention for the Prevention of Pollution from Ships) e dos seus Anexos e Códigos, bem como do ISM e dos ISPS, e de toda a regulação adotada pela IMO. Mencione-se, ainda, 
que a ICS possui forte relação com o IACS, seguradoras, o Grupo Internacional de Clubes de P\&I e outras agências especializadas marítimas, bem como organizações não governamentais cujas políticas e procedimentos possuem impacto no transporte marítimo. (ICS, 2009).

A ICS representa todos os setores da indústria global de transporte marítimo nas discussões dos foros internacionais, especialmente na IMO e proporciona: a) orientação nos desenvolvimentos da regulação e efetividade das normas do setor; b) promoção das melhores práticas, incluindo a produção de publicações especializadas, para a maioria dos países marítimos; c) a participação da sua associação de classe nacional como membro da ICS é como se fosse a participação automática do país na IMO e indica um sério envolvimento do país no transporte marítimo global. (ICS, 2009).

\subsubsection{International Shipping Federation (ISF)}

A ISF é a única entidade internacional dedicada os problemas marítimos que representa os empregadores e proporciona orientação e assessoria aos seus membros de forma direta ou por meio da sua rede de contatos global, inclusive a categoria de empregadores nos foros internacionais. A ISF é especializada na STCW Convention (Convenção sobre Padrões de Treinamento, Certificação e Serviço de Quarto para aquaviários) e orienta os seus membros no que tange aos seus detalhes técnicos, e seu secretariado apoia outras organizações internacionais, tais como a International Chamber of Shipping (ICS) e o International Maritime Employers' Committee (IMEC). (ISF, 2010) .

Além disso, a entidade é órgão consultivo da OIT, o qual co-coordena a posição dos armadores marítimos em todos os encontros e na IMO, bem como atua no acompanhamento da legislação nos Estados Unidos e participa, por meio da OIT, das reuniões do Memorando de Entendimento de Paris sobre Port State Control, e atua como membro ativo no International Committee on Seafarers' Welfare (ICSW) e possui contato regular com representantes dos sindicatos marítimos, incluindo a International Transport Workers 'Federation (ITF). (ISF, 2010). 


\subsection{Empresa Transnacional}

Além da concorrência desleal, do cartel e do contexto de liberalização dos transportes marítimos internacionais, ${ }^{11}$ nessa indústria, muitas empresas buscam reduzir custos, especialmente com o registro dos seus navios em países de bandeiras de conveniência, de forma que essas empresas podem ser consideradas transnacionais. ${ }^{12}$ Nesse sentido, é relevante a lição de José Cretella Neto (2006, p. 27) ao conceituar esse tipo de empresa como:

${ }^{11}$ Numa perspectiva liberal, com base, na política de liberalização do uso dos mares do holandês Hugo Grotius, autor de Mare Liberum sive de iure quod Batavis competit ad Indicana Commercia (1609), a qual não nos filiamos, e com o objetivo de estudar se o Direito Internacional contém regras gerais que, na ausência dos tratados específicos (bilateral, regional, internacional), limita a vontade dos governos para desenvolver políticas de transportes protecionistas: PARAMESWARAN, Benjamim. The Liberalization of Maritime Transport Services - With special reference to the WTO/GATS Framework. Hamburg: Springer, 2004. Sobre o tema, com a proposta dos organismos internacionais subsidiarem uma abertura mais ampla e confiável: COSTA, José Augusto Fontoura; DE ANDRADE, Thiago Pedroso. A Liberalização do Transporte Marítimo Internacional. In: CASTRO JUNIOR, Osvaldo Agripino de. (Org.) Temas Atuais de Direito do Comércio Internacional. Vol. I. Florianópolis: OAB/SC Editora, 2004, p. 209-244. A propósito, menciono a obra Mare clausum, seu de domino maris, do político e jurista inglês John Selden (1584-1654), publicada em 1634 para opor-se aos argumentos de Grotius, tendo em vista a pretensão dos holandeses de pescarem na costa inglesa.

12 Tais empresas buscam atuar em espaços deslegalizados, a fim de reduzir custos com tripulação, segurança, manutenção da embarcação e tributação, com grave risco ao meio ambiente e a vida humana no mar, bem como ofensa ao interesse público. Nesse sentido, é relevante mencionar a criação de uma linha de pesquisa no Programa de Mestrado e Doutorado em Ciência Jurídica da UNIVALI denominada Direito e Transnacionalidade. Sobre o tema: CRUZ, Paulo Márcio; STELZER, Joana. (orgs.). Direito e Transnacionalidade. Curitiba: Juruá, 2010. Mencione-se, ainda, a disciplina lecionada em 2009-II, juntamente com o Prof. Dr. Zenildo Bodnar, no Programa de Doutorado, denominada Dimensões Jurídicas Transnacionais, na qual se discute o papel do direito no mundo pós-crise de 2008 e do resgate do papel do Estado, dos organismos internacionais e dos atores não estatais na regulação dos espaços deslegalizados, por meio da reconstituição do Domínio Público Global, especialmente em face da estratégia da indústria de transportes marítimos, com as bandeiras de conveniência, dos crimes do sistema financeiro e dos poluidores do meio ambiente terrestre e aquático. 
[...] a sociedade mercantil, cuja matriz é constituída segundo as leis de determinado Estado, na qual a propriedade é distinta da gestão, que exerce controle, acionário ou contratual, sobre uma ou mais organizações, todas atuando de forma concertada, sendo a finalidade de lucro perseguida mediante atividade fabril e/ou comercial em dois ou mais países, adotando estratégia de negócios centralmente elaborada e supervisionada, voltada para a otimização de oportunidades oferecidas pelos respectivos mercados internos.

\section{Ademais:}

[...] grande parte da transnacionalização (no sentido de transposição a uma dimensão não-nacional, formal ou informal) do direito deve-se ao avanço irrefreável da Lex mercatoria. Este fluido econômico-comercial voga não somente sob a forma de acordos internacionais, mas também se infiltra, tal como a água, em ordens jurídicas nacionais cada vez mais permeáveis. Deste modo, a transnacionalização soaria antagônica ao Estado e ao direito. (VENTURA, 2009, p. 3).

\subsection{Navio}

O navio, espécie do gênero embarcação, é a ferramenta principal desse setor relevante da economia mundial, no qual o Direito e a Economia devem navegar juntos para que haja o seu desenvolvimento, mas para que isso ocorra é preciso que as instituições funcionem com eficácia, ${ }^{13}$ tendo como marco fundamental a Constituição Federal. ${ }^{14}$ Assim, as agên-

${ }^{13}$ Nesse sentido, a Análise Econômica do Direito é relevante. A economia institucional tem sido frequentemente descrita como uma revolta contra o formalismo. SPIEGEL, 1971, p. 629 apud MERCURO, Nicholas; MEDEMA, Steven G. Economics and the Law - From Posner to Post Modernism and Beyond. 2. ed. Princeton: Princeton University Press, 2006, p. 209.

${ }^{14}$ Sobre o tema: BUCHANAN, James M. The Domain of Constitutional Economics. In: MERCURO, Nicholas. (Ed.) Law and Economics. Critical Concepts in Law Public Choice. Vol. II. New York: Routlegde, 2007, p. 57-71. Acerca da teoria da escolha pública e a regulação dos contratos: O'HARA, Erin Ann. Opting out of regulation - A public choice analysis choice of Law. In: MERCURSO, Nicholas. (Ed.) Law and Economics. Critical Concepts in Law Public Choice, p. 209-256. 
cias reguladoras, como ANTAQ, ANVISA (Agência Nacional de Vigilância Sanitária) e ANTT (Agência Nacional de Transportes Terrestres), dentre outras, bem como departamentos do governo, como DPC (Diretoria de Portos e Costas) e SEP (Secretaria Especial dos Portos), possuem papel relevante, dialógico.

Nesse quadro, o direito e o Estado, num cenário de busca pela transnacionalidade, embora num cenário de combate ao terror, ${ }^{15}$ especialmente após 11 de setembro de 2001, ${ }^{16}$ exercem papel relevante na economia marítima, porque a regulação desse importante setor da economia mundial proporciona segurança jurídica ${ }^{17}$ e econômica ${ }^{18}$ para os altos valores in-

15 Sobre o tema: MORELLA JUNIOR, Jorge Hector. Transnacionalização e Segurança no Comércio Mundial: A importância do poder econômico na difusão das normas antiterrorista após 11 de setembro e sua implementação no Direito Brasileiro. Dissertação de Mestrado em Ciência Jurídica. Itajaí: UNIVALI, 2009. PLATCHEK, Ricardo Moisés de Almeida. As Bandeiras de Conveniência e a Segurança Mundial. In: CASTRO JUNIOR, Osvaldo Agripino de. (org.) Direito Marítimo Made in Brasil. São Paulo: Lex, 2007, p. 457-492. DIAS, Cristiano Gomes. A Pirataria e a Navegação Marítima. In: CASTRO JUNIOR, Osvaldo Agripino de. (org.) Direito Marítimo Made in Brasil, p. 493-520.

16 Nesse contexto, os navios de bandeira de conveniência, além de serem os maiores poluidores do meio ambiente marinho, por não se submeterem ao rigor fiscalizatório, são considerados mais propensos a serem usados pelos terroristas. Para aumentar a segurança no setor é necessária uma ação cooperativa multilateral.

17 Sobre o tema, na perspectiva norte-americana, por meio do estudo de casos, dentre os quais, o problema de aceitação da fraude; o efeito do ambiente e da cultura na confiança e na honestidade e implementação da confiança e da honestidade: FAGAN, Mark; FRANKEL, Tamar. Trust and Honesty in the Real World. A Joint Course for Lawyers, Business People and Regulators. Anchorage: Fathom, 2007, 224 p.

18 Sobre a efetividade de tais princípios: AGRAVO REGIMENTAL. SUSPENSÃO DE LIMINAR. AÇÃO CIVIL PÚBLICA. LESÃO À ORDEM PÚBLICA E ECONÔMICA CONFIGURADA. INSEGURANÇA JURÍDICA E RISCO BRASIL AGRAVADO. 1. No âmbito especial da suspensão liminar, cujos limites cognitivos prendem-se à verificação das hipóteses expressas na Lei $n^{\circ} 8.437 / 92$, art. $4^{\circ}$, descabem alegações relativas às questões de fundo. 2. Caracterizado o risco inverso, refletido no cenário de insegurança jurídica que pode se instalar com a manutenção da liminar, que, em princípio, admite a quebra do equilíbrio dos contratos firmados com o Poder Público, lesando a ordem pública administrativa e econômica e agravando o risco Brasil, defere-se o pedido de suspensão. 3. Agravo regimental provido. AgRg na SL 57 / DF. Rel. Min. Edson Vidigal. DJ 06/09/2004; REsp n. 201.726. 
vestidos e usuários do transporte marítimo. ${ }^{19}$ Ademais, o risco marítimo ${ }^{20}$ é inerente a tal atividade. Não é por acaso que o seguro dos dias modernos, tem origem no nauticum foenus, ou seja, no seguro marítimo.

A história do mundo está vinculada à história das grandes navegações. Por sua vez, os grandes sinistros marítimos sempre tiveram destaque na história dos povos, ${ }^{21}$ o que foi agravado pelos acidentes que causa-

${ }_{19}$ Para maior aprofundamento: CRUZ. Paulo Márcio. O Estado como principal sujeito da sociedade internacional. In: STELZER, Joana (org.). Introdução às Relações do Comércio Internacional. Itajaí: UNIVALI, 2007, p. 47-61. DE MACEDO, Paulo Emílio Vauthier Borges. Outros atores da sociedade internacional. In: STELZER, Joana (org.). Introdução às Relações do Comércio Internacional. Itajaí: UNIVALI, 2007, p. 81-94. DE OLIVEIRA, Odete Maria. Relações Internacionais e a questão dos seus paradigmas. In: STELZER, Joana (org.). Introdução às Relações do Comércio Internacional. Itajaí: UNIVALI, 2007, p. 95-113. CASTRO JUNIOR, Osvaldo Agripino de. As organizações internacionais: importância e características. In: STELZER, Joana (org.). Introdução às Relações do Comércio Internacional. Itajaí: UNIVALI, 2007, p. 63-79. FARIA, José Eduardo de. Poucas certezas e muitas dúvidas: o direito depois da crise financeira. São Paulo: Mimeo, 2009.

${ }^{20}$ Sobre a gestão da segurança e a análise do risco marítimo, por meio de estudo de casos de acidentes da navegação realizado pelo engenheiro naval norueguês: KRISTIANSEN, Svein. Maritime Transportation - Safety Management and Risk Analysis. London: Elsevier, 2008. E na União Europeia: BOISSON, Philippe. L'efficacité de la politique de l'Union Européenne em matière de sécurité maritime. In: GRARD, Loïe.(dir.) L'Europe des transports. Actes du colloque d'Agen Université Montesquieu-Bordeaux IV -7 et 8 octobre 2004. Paris: La Documentation Française, 2005, p. 645-662.

${ }_{21}$ Acerca do tema: WEISS, Jeffrey A. Maritime Disasters Through The Ages. In: Journal of Maritime Law \& Commerce. Vol. 32. n.2, April, 2001, p. 215-239. 
ram danos ambientais, como Exxon Baldez, ${ }^{22}$ Prestige $^{23}$ e Amoco Cadiz. Isso tem exigido, cada vez mais, normas mais rígidas para a segurança da navegação e proteção do meio ambiente marinho.

\subsection{Direito Marítimo: aspectos destacados}

A origem do Direito Marítimo é incerta, mas historiadores mencionam que normas jurídicas regulando o transporte marítimo datam do século XVIII a.C, no Código de Hamurabi. Pesquisadores sustentam que um sofisticado sistema internacional de Direito Marítimo existe desde a Idade Antiga no Mediterrâneo. (SCHOENBAUM apud TAYLOR, 20022003).

O Direito Marítimo é o conjunto ${ }^{24}$ de normas jurídicas que disciplinam as atividades necessárias para que as embarcações efetuem o trans-

\footnotetext{
22 Essa tragédia marítima que ocorreu em 24 de março de 1989, na costa do Alaska, derramou 11 milhões de galões de óleo cru nas águas do Prince William Sound, e afetou não somente o meio ambiente, mas arrasou a economia da região. O caso Exxon Shipping Co. $V$. Baker e mais 32.000 pessoas, todas autoras no $1^{\circ}$ grau, das quais $20 \%$ haviam falecido em 2008, ano do julgamento pela Suprema Corte dos Estados Unidos, envolveu o julgamento do valor da indenização por danos punitivos e de danos compensatórios (danos materiais). A Suprema Corte entendeu que os danos punitivos deveriam ser pagos na razão de 1:1 em relação aos danos materiais, o que reduziu a indenização em cerca de U\$ 2 bilhões. O valor da condenação ficou em torno de U\$ 1 bilhão. SCHOENBAUM, Thomas J. US Supreme Court Rules Punitive Damages Award Excessive. In: The Journal of International Maritime Law. Vol.13, 2008, p.199. Esse acidente fez com que os Estados Unidos adotassem uma política mais rigorosa de proteção ao meio ambiente marinho, especialmente contra o derramamento de óleo, e editassem no ano seguinte (1990) o Oil Pollution Act.

23 Esse acidente fez com que a IMO agilizasse a exigência de navios petroleiros com duplo casco. Acerca do tema: GALIANO, Elizabeth. In the Wake of the Prestige Disaster: Is and Earlier Phase-Out of Single-Hulled Oil Tankers the Answer? In: Tulane Maritime Law Journal. Vol. 28, 2003, p. 113-133.

24 A referência a conjunto indica a ordenação dessas normas em um sistema, evitando as contradições e as lacunas. JUSTEN FILHO, Marçal. Curso de Direito Administrativo. 4. ed. São Paulo: Saraiva, 2009, p. 1.
} 
porte pela via aquaviária. É uma disciplina jurídica autônoma, ${ }^{25}$ tendo inclusive, em face da sua relevância, obtido assento constitucional (artigo 22 , inciso I, da $\mathrm{CF} / 88$ ), e tem como objeto principal regular as relações jurídicas que se dão em torno do navio, ${ }^{26}{ }^{27}$ aqui considerado espécie de embarcação, ${ }^{28}$ por meio das relações jurídicas que se dão através dos contratos de transportes ${ }^{29}$ e de afretamento de embarcações, hipoteca naval, ${ }^{30}$ registro de embarcação, ${ }^{31}$ dentre outras.

${ }_{25}$ Trata-se do mesmo entendimento de: ARROYO, Ignacio. Compendio de Derecho Marítimo. 2. ed. Madrid: Tecnos, 2002, p. 22.

${ }^{26}$ Possui três requisitos não comuns a todas as embarcações: robustez, estanqueidade e vencer as fortunas do mar. Como espécie do gênero embarcação, todo navio é embarcação, mas nem toda embarcação é navio. Essa diferença é relevante, especialmente quando se trata de competência, tal como o artigo 109, IX, da CF/88: “Art. 109 - Aos juizes federais compete processar e julgar: IX - os crimes cometidos a bordo de navios ou aeronaves, ressalvada a competência da Justiça Militar;" Nesse caso, deve-se ter cautela, pois um crime ocorrido a bordo de uma embarcação de recreio, como iate ou lancha, não será julgado na Justiça Federal, por não se tratar de navio, mas de embarcação, sendo cabível o julgamento pela Justiça Estadual.

${ }^{27}$ Na terminologia náutica inglesa, o pronome pessoal é she (ela) e não it (coisa). O navio was nearer and dearer to the sailor than anyone except his mother. Acreditava-se que um navio era mais próximo e querido para o marinheiro do que qualquer pessoa, com a exceção de sua mãe. Segundo a tradição, haveria razão melhor do que essa para chamar seu navio de "ela"? A tradição marítima menciona, ainda, que o navio é o bem mais aguardado no cais, por vários grupos de homens, além de sua manutenção ter alto valor. ${ }^{28}$ Segundo o artigo $2^{\circ}$, inciso V da Lei n. 9.537, de 11 de dezembro de 1997, que dispõe sobre a segurança do tráfego aquaviário em águas sob jurisdição nacional e dá outras providências (Lei de Segurança do Tráfego Aquaviário - LESTA): “ $V$ - Embarcação qualquer construção, inclusive as plataformas futuantes e, quando rebocadas, as fixas, sujeita a inscrição na autoridade marítima e suscetivel de se locomover na água, por meios próprios ou não, transportando pessoas ou cargas."

${ }_{29}$ Considerado como aquele celebrado entre o embarcador (shipper) e o transportador (carrier) por meio do qual este se obriga, sob sua custódia, a transportar pela via aquaviária, de um porto a outro, mercadoria ou pessoa, e aquele se obriga a pagar uma remuneração por esse serviço, denominado frete.

30 É efetuada no Tribunal Marítimo, conforme Lei n. 2.180/54.

${ }^{31}$ Nos termos do artigo $2^{\circ}$, inciso XVIII da LESTA: "Registro de Propriedade da Embarcação - registro no Tribunal Marítimo, com a expedição da Provisão de Registro da Propriedade Marítima;" 
Se no Direito Marítimo, no Direito do Mar e no Direito da Navegação Marítima, a diferença entre navio e embarcação é relevante, para o Direito Tributário Marítimo, segundo Heleno Taveira Tôrres (2005, p. 397), ela inexiste:

A navegação marítima opera-se por navios e embarcações, mesmo que discutível essa distinção, e em matéria tributária completamente despicienda. Navio, usa-se para indicar o meio de realização dos atos constituídos nos respectivos contratos de transporte marítimo.

Mencione-se a relevância desse ramo do Direito Marítimo, vez que a carga da tributação no transporte marítimo no Brasil é alta. A tributação setorial não tem política nacional, vez que não somente a União e os estados, mas os municípios também procuram tributar as operações que envolvem indistintamente o modal.

Como o Direito Marítimo é aquele que trata da navegação comercial pelo meio aquaviário realizado por embarcações, inclui, portanto, a navegação de tais embarcações em rios, lagoas, canais, estreitos e baías.

Deve-se mencionar que o Direito Marítimo, direito misto, pois possui normas de direito privado e direito público, engloba o tráfico marítimo, que compreende a atividade de exploração comercial do navio, não se confunde, portanto, com o Direito da Navegação Marítima, inserido no direito público, porque possui como objeto o tráfego marítimo, que abrange o trânsito das embarcações, visando à segurança da navegação.

Trata-se de disciplina que, tendo em vista a natureza internacional do transporte aquaviário, possui alto grau de internacionalidade e complexidade, e que exige profissionais capacitados para lidar com as suas especificidades.

Nesse quadro, a Lei n. 9.537/1997 - LESTA - Lei de Segurança do Tráfego Aquaviário - é a principal norma que regula a segurança da navegação marítima e que deve ser regulamentada por decreto, o que foi feito pelo Decreto n. 2.256/1998 (Regulamento da LESTA - RELESTA). Ocorre que, com base na violação ao princípio da legalidade, o TRF da 
$4^{\mathrm{a}}$. Região, declarou que não subsistem multas aplicadas pela Autoridade Marítima à empresa que, segundo essa, violou o RELESTA.

Apelação Cível n. 2006.70.08.001267-3/PR. Relator: Des. Federal Edgard Antônio Lippmann Júnior. EMENTA. INFRAÇÕES. TRÁFEGO AQUAVIÁRIO. DECRETO No 2596/98. PRINCÍPIO DA LEGALIDADE. Não subsistem as multas aplicadas à Parte Autora com fundamento no Regulamento de Segurança do Tráfego Aquaviário, aprovado pelo Decreto $\mathrm{n}^{\mathrm{o}} 2596 / 98$, por ofensa ao princípio da legalidade. Decisão 25/09/2008.

O tráfego marítimo, pela sua abrangência e complexidade, é dotado de alto grau de transnacionalidade, como leciona Heleno Taveira Tôrres (2005, p. 402-403) porque:

[...] pela transnacionalidade de suas operações, envolve grande número de associações defensoras dos interesses de armadores, operadores ou trabalhadores. É o caso da International Shipping $\mathrm{Fe}$ deration (ISF), que congrega armadores de todo o mundo e cuja principal preocupação diz respeito ao preparo do pessoal para as funções de bordo; a International Chamber of Shipping (ICS), voltada para as questões vinculadas com a segurança dos navios e a poluição do meio marinho; a International Transport Federation (ITF), que reúne sindicatos de trabalhadores de bordo; o Baltic \& International Maritime Council (BIMCO), que congrega armadores, agentes, brokers e Clubes P \& I; entre outras de grande porte.

Por sua vez, no direito espanhol, segundo Ignacio Arroyo (2002, p. 22):

El Derecho marítimo es el conjunto de relaciones jurídicas que nacen o se desarrollan con el mar. Por consiguiente, el mar y lo marítimo constituyen los criterios delimitadores de la materia. Esa definición significa reconecer la autonomia de la disciplina, primero en el plano científico y después en los niveles legislativo, judicial y acadêmico o universitário; Y, por otra parte, el Derecho marítimo se concibe com um derecho general que incluye tanto aspectos de Derecho privado como público, nacional e internacional. Esa idea 
supone una concepción más amplia que la contemplada en los textos positivos (Código de Comercio principalmente) y en los planos de estudios de neustras Facultades de Derecho que trocean em Derecho marítimo entre Derecho Mercantil (las relaciones marítimas privadas) y el Derecho internacional público (El denominado Derecho público del mar).

\section{Direito Marítimo: relação com outros ramos do Direito, a Lex Mercatoria e a Lex Maritima}

O Direito Marítimo, em função da sua complexidade e regulação feita por organismos internacionais, é uma disciplina jurídica que se relaciona como várias outras disciplinas, como Direito do Mar, ${ }^{32}$ que abrange casos envolvendo os Estados, julgados pelo Tribunal Internacional de Direito do $\mathrm{Mar}^{33}$, e a proteção das riquezas no Domínio Marítimo ${ }^{34}$; Direito

\footnotetext{
32 Tem como objeto as relações jurídicas que se dão em torno do mar e como fontes do direito, a Convenção de Montego Bay, já ratificada pelo Brasil, pelo Decreto n. 1.650 e a Lei n. 8.617/1993, que dispõe sobre o Domínio Marítimo brasileiro. Essa disciplina tem potencial e assumirá cada vez mais importância com a exploração de petróleo e dos recursos marinhos da Amazônia Azul, expressão criada para simbolizar o tamanho do domínio marítimo brasileiro após o acréscimo de cerca de $1.000 .000 \mathrm{~km}^{2}$ à plataforma continental brasileira pela Comissão de Plataforma Continental da ONU.

${ }^{33}$ Criado pela Convenção das Nações Unidos sobre o Direito do Mar, em 1982, foi formalmente instalado em 1996. Dentre outras atribuições, no que tange à competência ratione materiae, o Tribunal tem competência para julgar: i) casos litigiosos sobre quaisquer disputas que: a) envolvam a interpretação ou aplicação da convenção, b) envolvam a interpretação ou aplicação de outros acordos, desde que tenham relação com a Convenção, c) envolvam a Câmara de Disputas dos Fundos Marinhos, d) envolvam a pronta liberação das embarcações e suas tripulações; e ii) competência consultiva. MICHELS, Gilson Wessler. Tribunal Internacional do Mar. In: BARRAL, Welber. (Org.). Tribunais Internacionais - Mecanismos Contemporâneos de Solução de Controvérsias. Florianópolis: Fundação Boiteux, 2004, p. 98-100.

${ }^{34}$ Sobre o processo histórico para chegar à cooperação internacional no mar, desde as consequências dos Tratados de Westfália, da Convenção Ramoge e Convenção de Montego Bay, com ênfase na proteção do meio ambiente marinho: DE BARROS, José Fernando Cedeño. Direito do Mar e do Meio Ambiente - A proteção das zonas costeiras
} 
da Navegação Marítima; ${ }^{35}$ Direito Portuário; ${ }^{36}$ Direito da Concorrência; Direito Internacional Público; Direito Internacional Privado, ${ }^{37}$ no qual a ordem pública, ${ }^{38}$ a fim de preservar a equidade nas relações contratuais

e litorais pelo Acordo Ramoge: Contribuições para o Brasil e Mercosul. São Paulo: Lex, Aduaneiras, 2007.

35 Tem como objeto as relações jurídicas que se dão em torno da segurança da navegação marítima, especialmente da salvaguarda da vida humana no mar. Suas principais fontes de direito são a Lei n. 9.537/1997 - Lei de Segurança do Tráfego Aquaviário - LESTA -, bem como convenções da International Maritime Organization, dentre os quais RIPEAM - Regulamento Internacional para evitar abalroamento no mar. A autoridade marítima brasileira, ou seja, o Comando da Marinha, por meio da Diretoria de Portos e Costas, é competente para a efetividade das normas. Sobre a disciplina: NETO, Pedro Duarte. A Autoridade Marítima e a Lei de Segurança do Tráfego Aquaviário. In: CASTRO JUNIOR. Osvaldo Agripino de. (Org.) Direito Marítimo Made in Brasil. São Paulo: Lex, 2007, p. 375-426. FILHO, Guilherme Alves de. O processo administrativo na Capitania dos Portos e no Tribunal Marítimo. In: CASTRO JUNIOR. Osvaldo Agripino de. (Org.) Direito Marítimo Made in Brasil. São Paulo: Lex, 2007, p. 427-256.

36 Tem como objeto o porto e como principais fontes do direito a Lei n. 8.630/1993, Lei de Modernização dos Portos, a Lei n. 10.233/2001, Lei de criação da ANTAQ, as Convenções Internacionais da OIT e da IMO, dentre as quais ISPS Code, bem como resoluções e atos administrativos da ANTAQ e da Secretaria Especial dos Portos. Sobre o tema, com 14 artigos: CASTRO JUNIOR, Osvaldo Agripino de; PASOLD, Cesar Luiz (orgs.). Direito Portuário, Regulação e Desenvolvimento. Prefácio Pedro Calmon Filho. Belo Horizonte: Forum, 2010, 474 p.

37 Para maior aprofundamento: ARROYO, Diego P. Fernández. Derecho Internacional Privado Comparado - Conceptos y Problemas Básicos del Derecho Internacional Privado. In: CASTRO JUNIOR, Osvaldo Agripino de. (Org.). Temas Atuais de Direito do Comércio Internacional. Vol. I. Florianópolis: OAB/SC Editora, 2004, p. 245-280. SALEME, Edson Ricardo; NIARARDI, George Augusto. Das cláusulas de hardship nos contratos internacionais. In: CASTRO JUNIOR, Osvaldo Agripino de (Org.). Temas Atuais de Direito do Comércio Internacional. Vol. II. Florianópolis: OAB/SC Editora, 2005, p. 389-406.

38 Acerca do aspecto transnacional da ordem pública, embora sustentemos que supranacionalidade é diverso de transnacionalidade, vez que aquela ocorre quando o Estado transfere o poder de regular para um organismo regional e esta, ocorre quando há espaço deslegalizado. JAYME, Erik. Identité Culturelle et Intégration: Le Droit International Privé Postmoderne - Cours Général de Droit International Privé. The Hague, Boston, London: Martinus Nijhoff, 2000, p. 231. Sobre o diálogo das fontes ( Le dialogue de sources): JAYME, Erik. Identité Culturelle et Intégration: Le Droit International Privé Postmoderne - Cours Général de Droit International Privé, p. 259. 
de transporte internacional, possui um relevante papel; Direito Ambiental; Direito Aduaneiro ${ }^{39}$; Direito Civil; Direito Comercial; além de outros ramos do conhecimento, como Engenharia Naval, Meteorologia, Física, Oceanografia, dentre outros.

Ressalte-se que, de acordo com Âke Modéer e Harry Scheiber, o Direito do Oceano (Ocean Law) e o Direito Marítimo mudaram bastante desde a II Guerra Mundial, especialmente a partir da década de 1970. (MODÉER; SCHEIBER apud MODÉER, 2007). Nesse sentido, segundo Âke Modéer (2007, p. 4/5, tradução por Osvaldo Agripino de Castro Junior ):

De forma crescente estamos trazendo leis globais para as águas oceânicas. Este conceito de transição tem uma história que inicia por volta de 1970, com a Conferência da ONU realizada em Estocolmo para o Meio Ambiente, em 1972. A partir dessa data que a geração do pós-guerra começou a contribuir na formulação da agenda para o futuro. Daquele ano até hoje, o direito internacional, direito público talvez mais do que direito privado, tem exercido um papel crescente e importante para os políticos e juristas. Como Laurence Juda escreveu em seu artigo, nós devemos "considerar o direito internacional como uma ferramenta para promover coerente e integrada gestão do espaço oceânico". Os legisladores, dessa forma, ainda possuem um importante papel na construção do Direito do Oceano. [...] Para a maioria dos juristas, o direito aplicado na terra tem sido considerado mais importante do que o Direito do Oceano. Aquele direito foi na era pré-moderna mais ou menos idêntico ao direito privado. Direito do Oceano, contudo, tem sido classificado tradicionalmente como direito internacional público, ius gentium. Historicamente os oceanos têm sido a infraestrutura para o transporte global e um requisito para a colonização das Índias e das Américas.

\footnotetext{
39 Acerca do tema, sob nossa orientação, inclusive com abordagem da pena de perdimento de embarcação: MADEIRA, Carlos Eduardo Camargo. A natureza jurídica da pena de perdimento por dano ao Erário no Direito brasileiro. Monografia de Especialização em Comércio Exterior - Universidade do Vale do Itajaí e Secretaria da Receita Federal. Itajaí: UNIVALI, 2007. Sobre o potencial de pesquisa da disciplina, com bibliografia básica: CASTRO JUNIOR, Osvaldo Agripino de. Direito Aduaneiro: Limites e possibilidades nas pesquisas dos Cursos de Direito. In: Consulex, v. 35, 2005, p. 22-24.
} 
Tais batalhas eram feitas para que houvessem regras de direito internacional público em face dos oceanos sem fronteiras, embora, fossem uma parte menor do problema do século XX. O processo de globalização tem dado novas dimensões a esta situação. Especialmente com dinâmicas entre macro e micro-relações, entre o local e o global, e nesta modernização, têm demonstrado diferenças entre as culturas política e jurídica. A tendência para harmonizar o direito internacional público com a ajuda de instrumentos jurídicos como convenções e declarações tem provocado conflitos entre conceitos culturais de diferentes tipos.

Mencione-se, ainda, a lição de Michael Taylor ao discorrer sobre a doutrina da liberdade dos mares, ${ }^{40}$ que é regulada pelo Direito do Mar, e sua importância para a economia dos países, da seguinte forma:

Liberdade dos mares, também conhecida como liberdade de navegação, está bastante consolidada no mundo atualmente. Ela vem sendo graduada com a aplicação histórica de doutrinas como a regra do tiro de canhão (agora incorporada pelo conceito de águas territoriais) e temas de preocupação nacional (como segurança da nação e meio ambiente), e o direito internacional determina que os Estados permitam o movimento dos navios. Contudo, a história demonstra que a doutrina da liberdade dos mares se funda num tênue equilíbrio entre o objetivo multilateral de promover o comércio e a auto-promoção dos interesses dos próprios Estados. Como discutido adiante, as fortes nações marítimas dos tempos modernos, ao contrário de usarem o poder naval, possuem a habilidade para usar ferramentas de comércio e medidas econômicas para promover suas agendas nacionais. (TAYLOR, 2002-2003, p. 154, tradução por Osvaldo Agripino de Castro Junior).

40 Deve-se mencionar, contudo, que para as potências marítimas, essa doutrina era bastante permissiva, porque permitia a países como a Grã-Bretanha, usarem o máximo do seu poder marítimo para maximizar os seus interesses nacionais no exterior. 


\subsection{Direito Marítimo e Lex Mercatoria}

Insiste-se, o Direito Marítimo não se confunde com o Direito Portuário, embora no cotidiano, por exemplo, muitas avarias ocorrem na armazenagem portuária ou no manuseio da carga fora do navio, de forma que é relevante identificar o INCOTERMS (International Commercial Term) para analisar as responsabilidades. ${ }^{41}$

Nesse cenário, segundo Tetley (2002, p. 4 , tradução por Osvaldo Agripino de Castro Junior):

O transporte marítimo tem provocado o desenvolvimento de uma importante parte do Direito Público e do Direito Privado. No Direito Privado, avaria geral, salvamento, afretamento e seguro marítimo estão entre os mais antigos princípios desenvolvidos como resposta a tais lutas do comércio marítimo, e que se difundiram princípios equivalentes nos países de tradição romano-germânica e anglo-saxônica. Esse conflito de leis cresceu, em larga medida, do comércio internacional em mares diversos, o que provocou na Europa Medieval, o nascimento da transnational Lex mercatoria (Law Merchant), incluindo a transnacional Lex maritima (maritime Law).

Acerca da Lex Mercatoria, Teubner (apud NEVES, 2006) sustenta que se trata de um direito corrupto, vulnerável a toda sorte de ataques. Indo além, Neves (2006) estima que as ordens correspondentes aos governos privados constituem direito trivializado pela economia mundial, o que requer ainda mais a intervenção do Estado na defesa do interesse público, caso haja conexão com o direito brasileiro, com base no princípio da ordem pública brasileira disposto no artigo 17 da LICC.

Uma sociedade hipercomplexa exige, ao menos, procedimentos complexos, o que demanda micro-sistemas jurídicos e, dessa forma, disciplinas jurídicas mais especializadas como o Direito Marítimo, com fon-

\footnotetext{
41 Acerca da integração das prestações próprias do operador portuário (na carga e descarga) no transporte marítimo de mercadorias e responsabilidades no direito espanhol: VARONA, Francisco Javier Arias. Manipulación Portuaria Y Daños a las Mercancías La responsabilidade extracontratual del operador portuario. Granada: Comares, 2006, p. 20-35.
} 
tes específicas e distintas de ramos tradicionais do direito, como Direito Penal, Direito Civil e Direito do Trabalho.

No Brasil, essas fontes do Direito Marítimo (quase $100 \%$ dependente das frotas de bandeiras estrangeiras, especialmente de conveniência) operadas e aplicadas de forma automática e acrítica pelos operados de direito, em regra, são decorrentes da produção feita no exterior da Lex Maritima. Tais usos e costumes carecem, portanto, de filtragem jurídica crítica que contemple a eficácia dos interesses, pela ordem, dos usuários brasileiros de transporte aquaviário e dos carriers de nacionalidade brasileira, também chamados na terminologia regulatória setorial de EBN's (Empresas Brasileiras de Navegação).

Nesse contexto, é relevante a lição de Arruda Junior (2007, p. 8):

O espaço acadêmico é importante, se não crucial, ao avanço compreensivo da realidade que se pretende conhecer. Problemática é a tendência acadêmica academicista (um contra-senso), a tal que do alto de confortável abrigo institucional ou, pretensamente sem partido da arena social, reduz a realidade que daí se vê contemplativa e isoladamente o artífice do trabalho intelectual universitário. O lugar da universidade é em essência o lugar de universalidades. O seu chão não paira sobre a realidade, a vida, ao contrário, só pelo estado das coisas como estão e são conservadas pode o mandarinato acadêmico, tendência diretiva na burocracia universitária, manter-se legítima e justificadamente como casta gratificada com o numerário dos contribuintes.

O Direito Internacional Privado é disciplina relevante para o Direito Marítimo, especialmente pela grande quantidade de nacionalidades existentes na expedição marítima, com grande potencial de conflito, o que demanda a necessidade de identificar lei e foro aplicáveis. ${ }^{42}$

42 Com ênfase nos problemas envolvendo os contratos de transporte marítimo, inclusive na União Europeia: LAMY, Eduardo de Avelar. Contrato de Transporte Marítimo Internacional: Legislação aplicável e competência. In: CASTRO JUNIOR, Osvaldo Agripino de (Org.). Temas Atuais de Direito do Comércio Internacional. Vol. II. Florianópolis: OAB/SC, 2005, p. 407-431. SILVÉRIO, Fernando; MAY, Otávia de Oliveira. A Cláusula de Eleição de Foro no Conhecimento de Transporte Marítimo (Bill 
Dessa maneira, deve-se mencionar que é comum a cláusula de eleição de foro no estrangeiro em contrato de transporte marítimo, todavia, o Supremo Tribunal Federal, historicamente tem interpretado a autonomia da vontade para eleição de foro, a fim de observar se o acordado foi a expressão inequívoca da vontade das partes.

Como exemplo, ao revisar decisão de instância inferior, o STF ao analisar o Recurso Extraordinário n. 18.615, julgado em 21 de junho de 1957, não considerou a citada cláusula de eleição de foro para Amsterdã, na Holanda, em contrato de adesão de transporte marítimo, ${ }^{43}$ vez que, de acordo com a doutrina francesa, a vontade é presumida e ocorre uma ficção, não há, portanto, concurso de vontades. Assim, segundo Nádia de Araújo (2002, p. 219):

No seu voto, o Min. Villas Boas esclareceu que tinha como perfeitamente válida a convenção que transfere o conhecimento das questões do gênero a uma jurisdição estrangeira, mas no caso não podia admiti-la porque inexistia uma prova cabal da vantagem que uma determinada cláusula daria a uma das partes no foro de Amsterdã, e por isso achou que a parte estaria mais protegida na jurisdição brasileira.

Sobre o tema, a jurisprudência do STF está consolidada no sentido de admitir a eleição do foro e a prorrogação, mas com algumas particularidades, cabendo destacar, segundo Franceschini (2002, p. 101):

of Lading). In: CASTRO JUNIOR. Osvaldo Agripino de. (Org.). Direito Marítimo Made in Brasil. São Paulo: Lex, 2007, p. 121-164. CALABUIG, Rosario Espinosa. Resolución de controvérsias y derecho aplicable em el transporte marítimo internacional: El caso de La Unión Europea. In: CASTRO JUNIOR, Osvaldo Agripino de (Org.) Temas Atuais de Direito do Comércio Internacional. Vol. II. Florianópolis: OAB/SC, 2005, p. 433-466.

${ }^{43}$ Ressalte-se que tal prática vem sendo efetuada até hoje pelos países que possuem grande frota mercante aos exportadores e importadores de países com pequena frota mercante, como o Brasil, inclusive determinando como lei aplicável a Convenção para Unificação de Certas Regras de Direito concernentes aos Conhecimentos Marítimos, provenientes da Convenção de Bruxelas, de 25 de agosto de 1924, assinada, mas não ratificada pelo Brasil, e as Regras de Haia, de 1968. 
[...] os acórdãos dos eminentes e saudosos Mins. Carlos Maximiliano, Sent. Estr. 993, de Portugal, RT 136/824; Hahnemann Guimarães, Sent. Estr. 1.080, DJ 09.08.1949, p. 2.035; Annibal Freire, Sent. Estr. 1095, DJ 24.09.1949, p. 3.003-3.004 com referência a minha opinião, Estudos, 726, e José Linhares, Arq. Jud. 45/298300 , 'mas sempre com as restrições da ordem pública e da fraude à lei' (parecer Proc. Geral acolhido, Arq. Jud. 73/88). Perdurou nessa diretriz, Sents. Estrs. 1.546, RTJ 10/401, 1.855, RTJ 34/404, 1.820, RTJ 35/155. E continuou nos últimos acórdãos, avultando-se os de lavra do eminente Min. Luiz Gallotti, Rec. Extr. 10.419, DJ 09.12.1950, p. 3.218, 'reconhecendo plenamente a submissão voluntária'; no Rec. Extr. 34.606, RTJ 4/313, não a admitindo com toda a procedência, 'nos contratos de adesão' (transportes, seguros etc) 'onde não existe um verdadeiro e inequívoco acordo de vontade'; e Sent. Estr. 1.649, DJ 23.04.1959, 380, 'prorrogação pelo comparecimento sem alegar a incompetência'.

Diante de tal quadro, pode-se sustentar que no Brasil é permitido o pactum de foro prorrogando expresso ou tácito, quando inexistir fraude à lei, violação aos princípios de ordem pública, desatenção aos limites da liberdade contratual em tema de Direito Processual Internacional ou ofensa aos princípios fundamentais de Direito das obrigações em matéria contratual. ${ }^{44}$

O acórdão do STF acima mencionado e analisado, ${ }^{45}$ bem como o REsp n. 302.212/RJ, julgado em 07.06.2005 ${ }^{46}$ e o Agravo Regimental

44 Sobre o tema, com maior profundidade especialmente no que tange aos contratos internacionais de compra e venda celebrados na internet, ver: CASTRO JUNIOR, Osvaldo Agripino de. Direito das Obrigações. Os Contratos Internacionais de Compra e Venda. In: FERREIRA JUNIOR, Lier Pires; CHAPARRO, Verônica Zarate (Coord.). Curso de Direito Internacional Privado. Rio de Janeiro: Freitas Bastos, 2006, p. 361-408. 45 Disponível em: <www.stf.jus.br>. Acesso em: 10 dez. 2010.

46 Segundo o julgado, desde que haja relação de consumo, é cabível o prazo prescricional de cinco anos do Código de Defesa do Consumidor no contrato de transporte marítimo. 
no REsp. n. 255.647/RJ, ${ }^{47}$ julgados no $\mathrm{STJ},{ }^{48}$ são relevantes decisões que apontam para a consolidação de um Direito Marítimo revigorado à luz da ordem pública brasileira e dos interesses dos usuários brasileiros dos serviços de transporte marítimo.

Assim, não se deve aceitar a eleição de foro sem qualquer conexão de caráter objetivo ou subjetivo admitido pelo Direito Processual Internacional, ${ }^{49}$ tão somente em decorrência da experiência ou tradição de um determinado foro em face da exigência da especialização de certas matérias, tais como a do foro inglês para as questões de Direito Marítimo, empréstimos em eurodólares ou relativas ao comércio internacional de grãos, dentre outros. ${ }^{50}$

A única exceção refere-se à possibilidade de eleição de juízo arbitral em país neutro diverso daquele cuja jurisdição esteja submetida a cada uma das partes litigantes, desde que se trate de disputa a respeito de matéria comercial e que envolva Estados ratificantes do Protocolo relativo às Cláusulas de Arbitragem, assinado em Genebra em 24 de setembro de 1923 (artigo $1^{\circ}$ do Protocolo), e ratificado no Brasil pelo Decreto n. 21.187, de 22 de março de 1932.

47 Não cabe o transportador alegar a exclusão da responsabilidade civil do transporte
marítimo com base em caso fortuito ou força maior em caso de avaria decorrente de mau
tempo ou borrasca, vez que é fato comum da navegação marítima.
48 Disponíveis em: <www.stj.jus.br>. Acesso em: 10 dez. 2010 .
49 Os elementos de conveniência de foro indicativos da competência internacional
rationi loci em matéria contratual devem ser reconhecidos como razoáveis pela ordem
jurídica pátria, dentre os quais, o domicílio, o local do cumprimento da obrigação, a
nacionalidade, o local da ocorrência do fato que gerou a obrigação.
50 Dentre os quais, citam-se os contratos de trabalho de estrangeiros residentes no Brasil,
celebrados por agências situadas em Macaé, Rio de Janeiro, representantes de empresas
norte-americanas que operavam para a Petrobrás na Bacia de Campos na década de 1990,
nos quais tivemos oportunidade de atuar como advogados. Tais working agreements
dispunham como foro de eleição a cidade de Cingapura, sem que houvesse qualquer
elemento de conveniência para determinar a competência (foro) ratione loci, vez que
a prestação de serviços se dava no domínio marítimo brasileiro (lex loci executionis),
portanto, aplicáveis o foro brasileiro e a legislação trabalhista pátria, para dirimir as
controvérsias decorrentes do descumprimento das convenções coletivas de trabalho das
categorias profissionais dos trabalhadores marítimos estrangeiros que atuam no offshore. 
Vale ressaltar que em uma compra e venda internacional, por exemplo, há várias espécies de relações jurídicas, todas elas gerando direitos e deveres para as partes. Dentre as relações, podemos citar: a) as que ocorrem entre os operadores e o fisco, em face da ocorrência dos fatos geradores que geram obrigação tributária, tal como o Imposto de Renda, e o Imposto de Importação; b) aquelas envolvendo operadores de comércio exterior, transporte marítimo e os operadores portuários que, algumas vezes, causam avarias às cargas e possuem o dever de indenizar; c) entre os exportadores e os importadores que, por estarem no exterior e acreditarem na impunidade, não honram o contrato com as empresas brasileiras, dentre outras.

O Direito Internacional Público ${ }^{51}$ que tem como objeto regular e uniformizar as relações jurídicas entre Estados e/ou organismos internacionais, por meio de tratados, considerados acordos celebrados por escrito entre dois ou mais Estados e/ou organismos internacionais. Trata-se da disciplina jurídica que, desde a fundação da ONU em 1945, com a assinatura da Carta da ONU, mais afetou o direito interno dos países. Com o aproveitamento para fins domésticos e pacíficos das tecnologias criadas na busca armamentista da Guerra Fria, como internet, jato, radar, computador, laser, dentre outras, os custos das comunicações e de transportes reduziram sobremaneira. Isso fez com que houvesse um aumento no comércio de bens e serviços bem como de viagens de pessoas.

Além disso, o DIP por meio do procedimento de aceitação tácita criado pela IMO, faz com que as convenções possam ser emendadas e implementadas, com um tempo mínimo, desde que não sofram oposição de uma quantidade de países. Assim, esse Instituto tem sido outro instrumento do DIP, dentre outros. Sem tais procedimentos, novos institutos que revolucionaram o Direito Internacional Público e Privado, a IMO não teria cumprido o papel relevante que vem exercendo desde sua criação e

${ }^{51}$ Acerca da relação do mar com o Direito Internacional Público, inclusive com menção às bandeiras de conveniência e ao meio ambiente marinho e à gestão da crise: $\mathrm{DE}$ BARROS, José Fernando Cedeño. Direito do Mar e do Meio Ambiente - A proteção das zonas costeiras e litorais pelo Acordo Ramoge: Contribuições para o Brasil e Mercosul. São Paulo: Lex, Aduaneiras, 2007, p. 51-194. 
seria, tão somente, um organismo internacional sem efetividade e desatualizado. (PAMBORIDES, 1997 ).

O Direito Internacional Público, portanto, é essencial no processo de segurança jurídica ao meio ambiente marinho e no combate ao comércio internacional injusto. Para Jacques Guillaume, a instância pública definitivamente deve retomar nas mãos aquilo que jamais deveriam ter perdido: o espírito da regulação. (GUILLAUME, 2008).

Não há, portanto, como confundir o Direito Marítimo com o Direito do Mar e Direito da Navegação Marítima, nem com o Direito Portuário. ${ }^{52}$ Aquela é uma disciplina autônoma, com objetos e fontes de direito diversos das disciplinas que foram mencionadas.

Além dessas disciplinas, o Direito Marítimo sofre grande influência do Direito da Regulação do Transporte Aquaviário e da atividade portuária, cujo objeto é a regulação setorial da atividade marítima, na qual se insere o navio e o porto, considerado o pulmão dos mares, local onde o navio carrega e descarrega suas mercadorias (goods).

\footnotetext{
52 Sobre a disciplina, decorrentes da produção do Grupo de Pesquisa Regulação da Infraestrutura e Juridicidade da Atividade Portuária: PASOLD, Cesar Luiz. Lições Preliminares de Direito Portuário. Florianópolis: Conceito Editorial, 2009. CASTRO JUNIOR, Osvaldo Agripino de. Aspectos jurídicos e políticos do processo de municipalização do Porto de Itajaí: uma experiência de luta pela cidadania. In: Revista Marítima Brasileira, v. 127, 2007, p. 153-165. E as seguintes dissertações de Mestrado em Ciência Jurídica do Programa de Mestrado e Doutorado em Ciência Jurídica da UNIVALI: CAPRARO, Milene Corrêa Zerek. Direito do Trabalho Portuário e Direito do Trabalho Maritimo: Estudos Introdutórios, 2010; HAECKLER, Gabriela. Portos Secos: Aspectos Jurídicos e Polêmicos destacados, 2009; RAMONIGA, Miriam. A natureza jurídica do órgão gestor de mão de obra: uma análise a partir da Lei $n$. 8630, de 25 de fevereiro de 1993, 2008. Sob nossa orientação no Programa de Mestrado: DE OLIVEIRA, Jackeline Daros Abreu. Responsabilidade Civil da União na Atividade Regulatória Portuária, 2009; COLLYER, Wesley Oliveira. A Lei de Modernização dos Portos e o Conselho de Autoridade Portuária: Estudo de caso de Itajaí, 2007; FRIEDRICH, Marlo Froelich. Limites e Possibilidades da Nova Lex Mercatoria no Direito Brasileiro, 2007; PLATCHEK, Ricardo Moisés de Almeida. Limites e Possibilidades de Aplicação do Código de Defesa do Consumidor no Contrato de Transporte Marítimo, 2007; TOMAZ, Roberto Epifanio. Limites e Possibilidades do Diálogo entre o Direito Empresarial e o Direito Comercial, 2006.
} 
O Direito da Concorrência também é relevante, especialmente pelas práticas protecionistas dos países em desenvolvimento, não obstante participem, regra geral, da OMC. Nesse cenário de desigualdade e práticas desleais, é relevante a lição de Pierre Bauchet (1998, p. 274): "Com o mercantilismo renascendo, o transporte pode não se tornar um elemento de 'bom comércio', mais um instrumento de dominação, como Colbert no passado dizia".

Direito Marítimo também se relaciona sobremaneira com o Direito Internacional Público, vez que como o navio navega em vários mares bem como se destina para vários portos em diversos países, além de ter uma nacionalidade própria e tripulação, muitas vezes com várias nacionalidades, sofre grande regulação dos tratados internacionais, especialmente os editados pela IMO, OIT (Organização Internacional do Trabalho) e OMC (Organização Mundial do Comércio), dentre outras.

O Direito Marítimo atua em espaços jurídicos diversos, e encontra tensão dialética entre o direito nacional e o direito internacional. ${ }^{53}$ Cabe acrescentar que o Direito Marítimo ainda possui ramos do direito voltados para os objetos das especificidades da atuação do navio, como Direito

${ }^{53}$ Sobre o direito nacional e o direito internacional, bem como acerca do Registro Internacional Francês (RIF) e diferença entre o internacional e o intracomunitário no transporte marítimo. CHAUMETTE, Patrick. Marine Marchande. Navegations et espaces juridiques. In: GUILLAUME, Jacques (org.). Les transports maritimes dans La mondialisation. Paris: Harmattan, 2008, p. 233-244. 
do Trabalho Marítimo, ${ }^{54}$ Direito Tributário Marítimo, ${ }^{55}$ Direito Previdenciário Marítimo e Direito Ambiental Marítimo. ${ }^{56}$

\section{Conclusão}

Por fim, pode-se concluir que:

a) O Direito Marítimo brasileiro é disciplina de direito privado que tem como objeto regular as relações jurídicas em torno do navio, como contrato de transporte, contrato de afretamento e responsabilidade civil, e que tem como fontes as convenções internacionais, o Código Civil, o Código Comercial e a Lex Maritima.

b) O Direito Marítimo não se confunde com o Direito da Navegação Marítima, Direito do Mar e Direito Portuário, que possuem como objeto, regular, respectivamente, as relações jurídicas que se dão em torno da segurança da navegação e da proteção do meio ambiente marinho (DNM), o mar, tal como a plataforma continental (DM) e o porto (DP).

c) As referências sugeridas no artigo visam contribuir para a difusão de tais disciplinas e melhor compreensão e efetividade do Direito Marítimo no Brasil, país com forte dependência desse setor de serviços, numa perspectiva crítica e que defenda os in-

\footnotetext{
${ }^{54}$ Acerca do tema: ZANINI, Gisele Duro. A Aplicação da Lex Fori nos Processos Trabalhistas dos Marítimos com Conexão internacional que laboram nos Espaços Marítimos Brasileiros. Dissertação de Mestrado - Programa de Doutorado e Mestrado em Ciência Jurídica da UNIVALI. Itajaí: UNIVALI, 2009.

${ }_{55}$ Sobre os aspectos tributários do transporte marítimo, inclusive com abordagem acerca do tonnage tax: TÔRRES, Heleno Taveira. Regime Jurídico das Empresas de transporte aéreo e marítimo e suas implicações fiscais. In: TÔRRES, Heleno Taveira (coord.). Comércio Internacional e Tributação. São Paulo: Quartier Latin, 2005, p. 395454. ADONNINO, Pietro. Aspectos Impositivos de las Empresas de Transporte Aéreo y Marítimo. In: TÔRRES, Heleno Taveira. Comércio Internacional e Tributação. São Paulo: Quartier Latin, 2005, 455-498.

${ }^{56}$ Para maior aprofundamento no tema, no direito brasileiro: CASTRO JUNIOR, Osvaldo Agripino de. Aspectos destacados da proteção ao meio ambiente marinho no Brasil. In: Revista de Direito Ambiental, v. 43, 2006, p. 222-245.
} 
teresses dos usuários de serviços de transporte marítimo (cargo owners) e das empresas de navegação brasileiras.

d) Não obstante o uso da Lex Maritima no Direito Marítimo brasileiro, esse deve ser recepcionado com a filtragem fundada na observância do princípio da ordem pública disposto no artigo 17 , da LICC, e no Código de Defesa do Consumidor, especialmente em face das cláusulas abusivas que tais contratos de transportes padronizados (adesão) possuem, com grave prejuízo aos usuários brasileiros.

e) Os julgados do STF e do STJ mencionados demonstram a possibilidade de aplicação do direito brasileiro, especialmente do Direito Marítimo e da LICC (artigo 17), para a defesa dos interesses dos usuários brasileiros de serviços de transporte marítimo internacional, de forma crítica.

\section{Referências}

ÂKE MODÉER, Kjell. Ocean Law and the process of Globalization. Law of the Sea Institute Occasional Paper \# 04 (2007). Institute for Legal Research. University of Califórnia. Berkeley, CA 94720-72 00. Disponível em: $<$ www.law.berkeley.edu/files/4-modeer--bringing_new_ law(2).pdf>. Acesso em: 31 jan. 2010.

ARAÚJO, Nádia de. Contratos Internacionais e a Jurisprudência Brasileira: Lei Aplicável, Ordem Pública e Cláusula de Eleição de Foro. In: RODAS, João Grandino. (coord.). Contratos Internacionais. 3. ed. São Paulo: Revista dos Tribunais, 2002, p. 195-229.

ARROYO, Ignacio. Compendio de Derecho Marítimo. 2. ed. Madrid: Tecnos, 2002.

ARRUDA JÚNIOR, Edmundo Lima de. Direito Alternativo e Contingência - História e Ciência - Manifesto. Florianópolis: IDACESUSC, 2007.

BAUCHET, Pierre. Les transports mondiaux, instrument de domination. Paris: Economica, 1998. 
BRASIL. Portal da Justiça Federal. Administrado pelo Conselho da Justiça Federal. Jurisprudência Unificada. Disponível em: <www.jf.jus. br/cjf>. Acesso em: 10 abr. 2010.

CRETELLA NETO, José. Empresa Transnacional e Direito Internacional. Exame do Tema à Luz da Globalização. Rio de Janeiro: Forense, 2006.

FRANCESCHINI, José Inácio Gonzaga. A Lei e o Foro de Eleição em tema de Contratos Internacionais. In: RODAS, João Grandino. (Coord.). Contratos Internacionais. 3. ed. São Paulo: Revista dos Tribunais, 2002, p. 66-121.

GUILLAUME, Jacques. Les transportes maritimes dans La mondialisation. In: GUILLAUME, Jacques (Org.). Les transports maritimes dans La mondialisation. Paris: Harmattan, 2008.

ICS. International Chamber of Shipping. Brochure. London: ICS, 2009.

ISF. International Shipping Federation. Disponível em: <http://www. marisec.org >. Acesso em: $1^{\circ}$ fev. 2010.

JUSTEN FILHO, Marçal. Curso de Direito Administrativo. 4. ed. São Paulo: Saraiva, 2009.

KENDALL, Lane C.; BUCKLEY, James J. The Business of Shipping. 7. ed. Centreville: Cornell Maritime Press, 2001.

LORANGE, Peter. Shipping Company Strategies - Global Management under Turbulent Conditions. London: Emerald, 2008.

MICHELS, Gilson Wessler. Tribunal Internacional do Mar. In: BARRAL, Welber. (Org.). Tribunais Internacionais - Mecanismos Contemporâneos de Solução de Co ntrovérsias. Florianópolis: Fundação Boiteux, 2004, p. 98-100. MOURA, Geraldo Bezerra de. Direito da Navegação. São Paulo: Aduaneiras, 1991.

NEVES, Marcelo. Entre Têmis e Leviatã: Uma relação difícil. São Paulo: Martins Fontes, 2006.

PAMBORIDES, George P. International Law and Its Impact on Private Shipping Law. In: RDHI, 1997 , v. 50, p. 183-204. 
SCHOENBAUM, Thomas J. US Supreme Court Rules Punitive Damages Award Excessive. In: The Journal of International Maritime Law. v. 13, 2008.

TAYLOR, J. Michael. Evaluating the Continuing GATS Negotiations Concerning International Maritime Transport Services. In: Tulane Maritime Law Journal. v. 27, 2002-2003.

TETLEY, William. International Maritime and Admiralty Law. Québec: Éditions Yvon Blais, 2002.

TÔRRES, Heleno Taveira. Regime Jurídico das Empresas de transporte aéreo e marítimo e suas implicações fiscais. In: TÔRRES, Heleno Taveira (Coord.). Comércio Internacional e Tributação. São Paulo: Quartier Latin, 2005.

VENTURA, D. F. L. Hiatos da transnacionalização na nova gramática do Direito em rede: um esboço de conjugação entre estatalismo e cosmopolitismo. In: MORAIS, José Luiz Bolzan de; STRECK, Lênio (Org.). Anuário do Programa de Pós-Graduação em Direito. Porto Alegre: Livraria do Advogado, v. 4, p. 89-107, 2007.

Recebido em: 09/09/2010 Revisado em: 22/09/2010 Aprovado em: 08/11/2010 